\title{
Ampliação da jornada escolar e dever de casa: denúncias cruzadas*
}

\author{
Extension of school day and homework: crossed denouncements
}

Ampliación de la jornada escolar y deber de casa: denuncias cruzadas

TÂNIA DE FREITAS RESENDE**

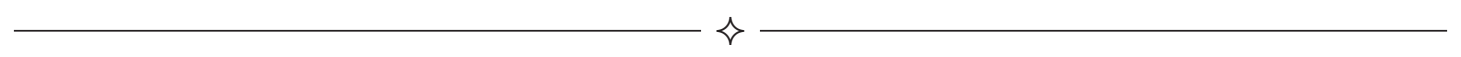

\begin{abstract}
RESUMO
Muitos programas de ampliação da jornada escolar no ensino fundamental têm sido desenvolvidos, no Brasil, no formato conhecido como turno e contraturno. Nesse cenário, diversas polêmicas surgiram a respeito dos deveres de casa. Tais polêmicas expressam desafios mais amplos relativos à implementação dos programas e à própria realização desses deveres na tradição escolar. Assim, as questões relativas ao dever de casa "denunciam" desafios inerentes ao modo como a escola de tempo integral tem sido implementada; e a implantação dos programas de tempo integral acaba por "denunciar" desafios relativos ao dever de casa, que antecedem as políticas de ampliação da jornada. O objetivo do artigo é analisar essas "denúncias cruzadas", utilizando dados recolhidos em atividades de extensão universitária e de pesquisa desenvolvidas na Região Metropolitana de Belo Horizonte.
\end{abstract}

Palavras-chave: Escola de tempo integral. Dever de casa. Turno e contraturno.

\begin{abstract}
Many programs to extend the school day in primary school are being developed in Brazil in the format known as shift and countershift. In this scenario, several controversies have surfaced regarding homework. These controversies express broader challenges regarding the implementation of these programs and the practice of homework in our school tradition. Thus, the issues related to homework "denounce" inherent challenges to the way full time school programs are being implemented; and the implementation of full-time programs ends up "denouncing" challenges related to homework, which precede the policies to extend school day. The purpose of this article is to analyze these "cross-denunciations", using data collected in university outreach and research activities developed in the Metropolitan Region of Belo Horizonte.
\end{abstract}

Keywords: Full time school. Homework. "Shift and countershift".

\section{RESUMEN}

Muchos programas de ampliación de la jornada escolar en la enseñanza fundamental han sido desarrollados, en Brasil, en el formato conocido como turno y contra turno. En ese escenario, varias polémicas han surgido respecto a los deberes de casa. Tales polémicas expresan desafíos más amplios relativos a la implementación de esos programas ya la propia práctica de los deberes de casa en nuestra tradición escolar. Así, las cuestiones relativas al deber de casa "denuncian" desafíos inherentes al modo en que la escuela de tiempo completo ha sido implementada; Y la implantación de los programas de tiempo completo acaba por "denunciar" desafíos relativos al deber de casa, que anteceden a las políticas de ampliación de la jornada. El objetivo del artículo es analizar esas "denuncias cruzadas", utilizando datos recogidos en actividades de extensión universitaria y de investigación desarrolladas en la Región Metropolitana de Belo Horizonte.

Palabras clave: Escuela de tiempo completo. Deberes de la casa. Turno y contraturno.

\footnotetext{
*Este artigo deriva de pesquisa financiada pelo acordo Capes/Fapemig (Edital 13/2012 Fapemig) e pelo Obeduc/Capes, por meio do Observatório da Educação (Edital Capes Obeduc 2012).

**Doutora em Educação. Professora de Sociologia da Educação no Departamento de Ciências aplicadas à Educação da FaE/UFMG. Pesquisadora do Observatório Sociológico Família-Escola (OSFE).E-mail: taniaresbr@gmail.com
} 


\section{INTRODUÇÃO}

Foram implantados nos últimos anos, no Brasil, especialmente no âmbito das redes municipais e estaduais de ensino, diversos programas que estendem o tempo diário de permanência das crianças e jovens em atividades educativas realizadas na escola ou sob a coordenação desta. Esses programas apresentam diferentes concepções e formatos (BRASIL, 2010a; CAVALIERE, 2007), revelando formas diversificadas de compreender a educação integral, de atender a demandas da própria educação e da comunidade, bem como de organizar os tempos, os espaços, o currículo, de alocar sujeitos e implementar (ou não) parcerias e obter financiamento.

Uma pesquisa encomendada pelo Ministério da Educação e realizada por um grupo de universidades brasileiras identificou, no ano de 2009, em todo o território nacional, 800 experiências de ampliação da jornada escolar, desenvolvidas em 500 municípios ${ }^{1}$. Desse conjunto de experiências mapeadas, $45,5 \%$ tinham jornada diária de oito horas ou mais e $10 \%$ ofereciam uma jornada entre sete e oito horas diárias. Ou seja, a maior parte dos programas identificados $-55,5 \%$ ou 444 - situava-se dentro do que a legislação brasileira define como "tempo integral", isto é, uma jornada igual ou superior a sete horas diárias². Segundo o Censo Escolar 2015, o Brasil contava, naquele ano, com 4,5 milhões de alunos que cumpriam essa jornada escolar no ensino fundamental ${ }^{3}$.

Considerando a forte tradição brasileira de funcionamento da escola em turnos de cerca de quatro horas diárias, uma jornada com duração de sete horas ou mais tem diversos tipos de desdobramentos, impactando o funcionamento da instituição escolar em aspectos que vão desde a alimentação e higiene dos alunos até o currículo, passando por outros, como a organização do tempo e dos espaços, os profissionais envolvidos e a organização de seu trabalho, a adequação da estrutura e dos recursos. Do ponto de vista político-pedagógico, o "tempo integral" reapresenta questões centrais no campo da educação, tais como a das funções sociais da escola e a da divisão do trabalho educacional entre família e escola.

\footnotetext{
${ }^{1}$ A pesquisa (BRASIL, 2010a) contemplou apenas as redes municipais de ensino, de modo que as experiências das redes estaduais não estão incluídas nos dados obtidos. O número maior de experiências (800) do que de municípios em que elas se realizam (500) explica-se pelo fato de que há municípios que desenvolvem diferentes projetos de ampliação da jornada escolar.

2 Segundo a legislação, considera-se "educação básica em tempo integral a jornada escolar com duração igual ou superior a sete horas diárias, durante todo o periodo letivo, compreendendo o tempo total que um mesmo aluno permanece na escola ou em atividades escolares" (BRASIL, 2007 - Decreto n. 6.253/2007, art. 4o, grifos da autora).

3 Dados do Inep/MEC. Disponível em: < http://portal.mec.gov.br/index. php?option $=$ com docman $\&$ view $=$ download $\&$ alias $=36521$-apresentacaocenso-escolar-divulgacao-22032016-pdf\&Itemid $=30192>$. Acesso em: 6 jan.2017.
}

Nesse cenário, uma prática pedagógica que já se mostrava polêmica no contexto dos turnos parciais tem suscitado novos debates no âmbito da escola de tempo integral: os deveres de casa. Compreendidos como atividades pedagógicas prescritas por professores para serem realizadas pelos alunos fora do período de aulas, em geral no contexto doméstico, os "deveres de casa", "lições de casa" ou "tarefas para casa" constituem uma prática já tradicional e até mesmo naturalizada no contexto escolar (PAULA, 2000; HENRIQUES, 2007; RESENDE, 2012). Ao envolver conjuntamente a família e a escola, constituem um importante elo de ligação entre essas duas instâncias socializadoras e congregam em sua realização, ao mesmo tempo, as dimensões de complementaridade e de conflito existentes entre elas. As polêmicas relativas ao dever de casa manifestam-se tanto nas escolas e na mídia de modo geral quanto na literatura científica sobre o tema, na qual se discute a validade ou não de prescrever lições de casa, o seu impacto no desempenho acadêmico, as suas consequências em termos de equidade ou iniquidade educacional, dentre outras questões (CARVALHO, 2000; NOGUEIRA, 2002; CARVALHO, 2004; RESENDE, 2008; RAYOU, 2009; DESLANDES, 2009; RESENDE, 2013).

Quando se amplia a jornada escolar diária da criança ou do adolescente, de aproximadamente quatro horas para sete ou mais horas, novas questões em relação ao dever de casa se colocam. Faz sentido e é pertinente, nesse novo contexto, continuar prescrevendo deveres? Os objetivos antes cumpridos pelos deveres podem ser assegurados dentro da jornada letiva, possibilitando a supressão das lições extra-aula? Se mantidos, quais seriam os objetivos dos deveres? Eles continuariam sendo realizados em casa, após a jornada letiva integral? Ou haveria na escola um tempo para sua realização? Que tempo seria esse, como seria organizado, com o acompanhamento de que tipo de profissional? O que essas mudanças poderiam significar do ponto de vista da relação com as famílias e da divisão de trabalho educacional entre estas e a escola? De que modo envolvê-las no acompanhamento à escolaridade dos filhos?

Essas questões foram insistentemente levantadas em atividades de pesquisa e de extensão desenvolvidas pela autora em torno de projetos de ampliação da jornada escolar na Região Metropolitana de Belo Horizonte, nos últimos dez anos. Tratava-se, na maior parte dos casos, de programas de ampliação da jornada com uma característica em comum: a escola mantém os dois turnos de "ensino regular", organizados tal como antes da implantação do programa, e amplia as oportunidades educativas oferecidas a uma parte de seus alunos ao ofertar atividades diversificadas no turno contrário àquele no qual têm aulas regulares - ou seja, no chamado 
"contraturno". Essas atividades assumem, comumente, o formato de oficinas, ampliando o currículo escolar com a introdução de uma diversidade de conteúdos nos campos das artes, dos esportes, da música, da cultura popular, entre outros. Além disso, oficinas de acompanhamento pedagógico ou reforço escolar frequentemente envolvem o apoio à realização dos deveres de casa pelos alunos, no espaço-tempo de ampliação da jornada escolar.

Essa tem sido uma modalidade de ampliação da jornada escolar bastante utilizada nas redes públicas de ensino: na pesquisa de âmbito nacional financiada pelo MEC, já mencionada neste texto, as atividades relacionadas à ampliação da jornada escolar eram realizadas, em $80,1 \%$ das experiências mapeadas, no turno contrário ao da oferta das disciplinas do currículo escolar tradicional (BRASIL, 2010a). Pode-se supor que um dos motivos para tal predominância é que grande parte das experiências são iniciadas sem contemplar todos os alunos de determinada rede de ensino ou de determinada escola direcionando-se para aqueles em situação de maior vulnerabilidade ou risco social. Nessa situação, o formato que vem sendo chamado de "turno e contraturno" passa a ser adotado como estratégia viabilizadora da ampliação da jornada, uma vez que, para mesclar ao longo do dia as diferentes atividades, tais como aulas e oficinas, é necessário abranger todos os alunos, o que exige infraestrutura e investimentos maiores.

Observa-se que, nessa forma de organização, além de questões necessariamente colocadas em relação ao dever de casa em toda escola de tempo integral - por exemplo, manter ou não os deveres, considerando a grande carga horária letiva -, apresentam-se outras, mais específicas. Suprimir ou não o dever de casa, por exemplo, torna-se uma decisão mais complexa quando uma parte dos alunos frequenta a escola em horário integral, e a outra parte, em turnos parciais. Quando a opção é por manter a prescrição dos deveres de casa e orientar os estudantes da jornada de tempo integral a realizá-los na escola, muitos desafios são frequentemente apontados pelos educadores responsáveis pelo turno de ampliação da jornada:

- frequentemente, a enturmação é diferente no turno e no "contraturno", podendo haver, em uma mesma turma do contraturno, diferentes deveres a serem realizados, dificultando o acompanhamento;

- muitos projetos envolvem a contratação de monitores ou agentes culturais para a realização de oficinas, e esses profissionais nem sempre se sentem preparados para acompanhar a realização dos deveres de casa pelos alunos;

- há projetos que utilizam espaços diversificados na escola e na cidade para a realização das atividades de ampliação da jornada (quadras, praças, salas sem mobiliário, etc.) e nem sempre esses espaços são adequados para a realização dos deveres de casa;

- muitas vezes, há dificuldades de comunicação entre os profissionais do turno e do contraturno, o que dificulta a realização de um trabalho mais integrado em relação aos deveres; e, não raro, ouvem-se queixas recíprocas (os profissionais que acompanham os deveres apontam problemas na elaboração e na quantidade; os professores do turno avaliam que o acompanhamento não é satisfatório).

Em decorrência dessas e de outras questões, o dever de casa chegou a ser caracterizado por alguns educadores, em encontros realizados para discutir especificamente esse assunto 4 , como "o Calcanhar de Aquiles" da escola de tempo integral ou "o grande nó" do processo de ampliação da jornada escolar. Essa afirmação pode soar como um exagero, considerando-se que as tarefas de casa tendem a ser vistas - tanto na escola de tempo parcial quanto na de jornada ampliada - apenas como um detalhe do processo pedagógico. Entretanto, a análise das falas desses educadores, bem como da literatura referente ao tema, indica que não se trata de exagero ao se considerar que o dever de casa "está na encruzilhada de numerosos fenômenos constitutivos do mundo escolar e de suas relações com o resto da sociedade" (RAYOU, 2009, p. 10, tradução da autora). Nesse sentido, as questões a este concernentes, embora possam à primeira vista parecer de importância relativamente pequena, revelam tensões que perpassam centralmente a educação escolar, tais como a divisão de trabalho educacional entre família e escola, as definições curriculares e as relações entre estas e o desempenho escolar dos alunos. No caso das experiências de jornada ampliada descritas acima, é interessante observar que o dever de casa passa a estar "na encruzilhada" entre os chamados "turno e contraturno", constituindo o principal elemento de interação entre ambos e catalisando tensões que emergem nessa nova forma de organização (e de divisão) do trabalho escolar.

Este artigo parte do pressuposto de que as dificuldades enfrentadas com relação aos deveres de casa no contexto da ampliação da jornada escolar são expressões de desafios mais amplos relacionados, por um lado, à implementação dos programas no formato acima descrito; e, por outro, à própria prática de prescrição e de realização dos deveres de casa, tal como vem se desenvolvendo na tradição

\footnotetext{
4 Trata-se de encontros de educadores ligados a programas de ampliação da jornada escolar em redes municipais de ensino, na Região Metropolitana de Belo Horizonte, para os quais a autora deste texto foi convidada, entre os anos de 2010 e 2015, com o objetivo específico de discutir a questão dos deveres de casa na escola de tempo integral. A realização desses encontros, por si, já denota a extensão do problema na percepção dos atores envolvidos.
} 
escolar. Ou seja, as questões que o dever de casa coloca para a escola de tempo integral "denunciam" desafios inerentes ao modo como esta vem se configurando em muitas redes de ensino; e a implantação dos programas de tempo integral, no contexto acima descrito, acaba por "denunciar" desafios relativos ao dever de casa, os quais antecedem as políticas de ampliação da jornada escolar. O objetivo do artigo é analisar essas "denúncias cruzadas", discutindo alguns desafios relativos tanto aos programas de ampliação da jornada quanto ao dever de casa como prática pedagógica. Não se pretende, portanto, responder às questões anteriormente enunciadas sobre a prescrição das tarefas de casa no contexto dos projetos de ampliação da jornada escolar, nem apresentar soluções específicas. Mas, sim, contribuir para essa discussão por meio de um aprofundamento em torno dos dois elementos que mobilizam as referidas questões: os projetos de ampliação da jornada e os deveres de casa.

Assim, no próximo tópico deste texto discutem-se algumas denúncias do dever de casa a respeito dos projetos de ampliação da jornada escolar; no seguinte, aborda-se o inverso: algumas denúncias dos projetos de ampliação da jornada a respeito da prática dos deveres de casa. Nos dois tópicos são utilizados, como material empírico, dois tipos de dados. O primeiro tipo refere-se a depoimentos que representam falas de educadores envolvidos em projetos de ampliação da jornada escolar, durante encontros de formação coordenados pela autora deste texto, nos quais foi debatida a questão dos deveres de casa ${ }^{5}$. Os demais dados foram colhidos no contexto de uma pesquisa realizada, em 2014, na Região Metropolitana de Belo Horizonte (RMBH), nos municípios de Belo Horizonte, Contagem, Ribeirão das Neves, Lagoa Santa, Ibirité, Sabará6. A pesquisa teve como objetivo diagnosticar de que maneira a questão do dever de casa tem sido tratada no âmbito dos projetos de ampliação da jornada escolar desenvolvidos nesses municípios, envolvendo a aplicação de questionários digitais a 206 profissionais de 173 escolas $^{7}$. Todas essas escolas desenvolviam, naquele momento, projetos de ampliação da jornada no formato "turno e contraturno", atendendo as crianças matriculadas nesses projetos durante sete ou mais horas diárias, cinco dias por semana. Dentre os profissionais que responderam ao questionário, 109 (52,9\%) eram responsáveis pelo

\footnotetext{
${ }^{5}$ Encontros mencionados na nota 6. Os trechos que representam falas dos educadores durante esses encontros de formação não constituem transcrições literais (uma vez que não houve gravação), mas anotações que recuperam o conteúdo das questões apresentadas.

6 Foram contatados para a pesquisa todos os municípios da RMBH que, em 2014, possuíam pelo menos dez escolas desenvolvendo projetos de ampliação da jornada. O município de Betim, contatado, não forneceu autorização em tempo hábil para a realização da pesquisa.

7 Os questionários digitais foram enviados para 734 profissionais de 356 escolas, tendo sido respondidos por 206 profissionais de 173 escolas.
}

programa de tempo integral da escola, $69(33,5 \%)$ eram coordenadores ou supervisores pedagógicos do turno regular e $28(13,6 \%)$ acumulavam essas duas funções. Os questionários envolviam tanto itens de resposta fechada quanto espaços para observações dos respondentes, sendo alguns resultados utilizados para as discussões a seguir. Para facilitar as referências, esta pesquisa é doravante designada, neste texto, como "Pesquisa na Região Metropolitana de Belo Horizonte" ou "PRMBH".

\section{DENÚNCIAS DO DEVER DE CASA SOBRE OS PROJETOS DE AMPLIAÇÃO DA JORNADA ESCOLAR}

\begin{abstract}
A. Temos uma grade definida para o contraturno, com seis oficinas que se distribuem em rodízio durante a semana, nenhuma delas contemplando especificamente os deveres de casa. Como fazer o dever de casa numa oficina de biscuit? De esportes? Como fazê-lo em oficinas que são realizadas em quadras ou em espaços abertos? (Questionamento da coordenadora de um projeto de ampliação da jornada escolar, durante Roda de Conversa - Belo Horizonte, 2010).
\end{abstract}

O questionamento acima, feito por uma educadora envolvida em um projeto de ampliação da jornada escolar, sinaliza uma situação na qual, no momento de implantação desse projeto, nem a questão do dever de casa (e, com ela, outras questões referentes ao ensino regular) e nem a proposta curricular do tempo ampliado foram discutidas conjuntamente pelas equipes da escola. Definiu-se uma "grade" de oficinas para o "contraturno" sem levar em conta os deveres (e outras eventuais demandas do "ensino regular") e mantiveram-se os deveres sem levar em conta o contraturno. O problema só veio a ser constatado depois, durante o funcionamento das oficinas.

Essa situação tem se repetido em diversas escolas e redes de ensino. A estratégia mais comum para enfrentá-la tem sido reservar algum tempo do contraturno para a realização dos deveres. Nas escolas participantes da pesquisa PRMBH, na maior parte dos casos, acontecem momentos de realização dos deveres no contraturno escolar, seja por todos os alunos que participam do programa de ampliação da jornada (31,5\% das respostas), seja por alguns deles $(22,5 \%)$, ou seja, ainda, em alternância com a realização de deveres no espaço doméstico (27\%). É muito reduzido o número de respondentes segundo os quais os deveres são realizados sempre em casa (7,5\%). Mas, mesmo assim, os problemas não estão solucionados, como indicam estes depoimentos colhidos na mesma pesquisa, por meio dos questionários digitais respondidos pelos coordenadores de programas de ampliação da jornada escolar: 
B. A integração com a escola [referindo-se ao ensino regular] é difícil, não conseguimos momentos para reuniões. A oficina reúne alunos de várias turmas diferentes do ensino regular. O aluno de uma turma chega na oficina e diz que não tem dever de casa, o monitor não tem como saber se é verdade ou não, não sabe qual é o dever... (coordenadora do contraturno, PRMBH, 2014).

C. Pedimos aos professores que nos comuniquem as principais dificuldades do estudante e quando este não fizer o Para Casa. Temos um grupo de professoras que trabalha em parceria conosco, porém alguns não fazem questão de participar (coordenadora do contraturno, PRMBH, 2014).

D. Já tentamos algumas reuniões [com a equipe do ensino regular], mas a falta de tempo nas escolas não nos permite chegar a nenhuma solução viável (coordenadora do contraturno, PRMBH, 2014).

Há, também, situações em que os educadores do turno ampliado não aceitam responsabilizar-se pelos deveres, considerando que essa não seria a proposta da ampliação da jornada:

E. Acho necessário o acompanhamento dos pais no dever de casa. O filho passa nove horas na escola e este é o momento que os pais têm para acompanhar o filho no seu processo de aprendizagem. O objetivo do Programa Escola Integrada não é continuar o processo de ensino da escola regular e sim dar ao aluno novas perspectivas de aprendizagem no que diz respeito à sua formação integral como ser humano e cidadão (coordenadora do contraturno, respondendo ao questionário digital - PRMBH, 2014).

F. A escola no contraturno não deve ser uma repetição da escola do turno regular. O papel da jornada ampliada é trabalhar não conteúdos, mas habilidades diferenciadas (coordenadora do contraturno, em encontro de discussão sobre o dever de casa na escola de tempo integral-Betim, 2013).

Nesses casos, está subjacente a ideia de que as oficinas do turno ampliado teriam por objetivo a diversificação das oportunidades formativas oferecidas aos alunos, possibilitando o desenvolvimento de habilidades diferentes daquelas trabalhadas no turno regular. Constata-se, entretanto, que o esforço de diferenciação pode levar a um reforço da fragmentação do trabalho, incorrendo-se inclusive em dicotomias perigosas, se não mesmo equivocadas, como a que polariza "conteúdos" e "habilidades" como se fossem objetos de ensino e aprendizagem mutuamente excludentes.

Observa-se que, para além das dificuldades de comunicação apontadas nos depoimentos B, C e D, os depoimentos $\mathrm{E}$ e $\mathrm{F}$ sinalizam uma questão mais complexa, que é a da divisão e/ou do compartilhamento de tarefas e responsabilidades entre os chamados "turno" e "contraturno". Nesse sentido, as questões em relação ao dever de casa não se esgotam em si mesmas, mas acabam denunciando as condições em que vêm sendo implementados diversos projetos de ampliação da jornada escolar. Condições essas que têm consequências para além das dificuldades relativas aos deveres.

De fato, no modelo de ampliação da jornada escolar contemplado neste texto, os chamados turno e contraturno têm tido, de modo geral, funcionamento praticamente independente, com planejamentos específicos para cada um e diferentes equipes responsáveis. Ao se optar pela implantação de um projeto de jornada ampliada para uma parte dos alunos da escola, constitui-se uma equipe responsável pelo que passa a se chamar, a partir de então, de "projeto". Essa equipe, em geral, define tanto a proposta curricular desse projeto quanto a sua dinâmica de funcionamento, sem que este seja visto como um tema para discussão por todo o coletivo de educadores da instituição ${ }^{8}$.

O "ensino regular", por sua vez, continua se desenvolvendo tal como antes da implantação do programa de ampliação da jornada, por meio de aulas das diferentes disciplinas, no âmbito das quais os deveres de casa são prescritos ou não, conforme os critérios de cada professor ou de acordo com a proposta pedagógica da escola. No outro turno, realizam-se as oficinas, seguindo seu planejamento específico, ministradas por diferentes tipos de profissionais, como agentes culturais, estagiários, estudantes de universidades, ou até mesmo por voluntários. Existe, na maior parte dos programas, um coordenadorgeral para o turno de ampliação da jornada - chamado de "professor comunitário", "gestor", "coordenador do tempo integral" ou outras denominações, conforme o projeto -, enquanto, no "ensino regular", outros profissionais, como coordenadores pedagógicos e supervisores, continuam respondendo pelo trabalho pedagógico. Nesse contexto, os deveres de casa passam a constituir o principal - e, em muitos casos, o único - dispositivo pedagógico que "transita" entre os dois contextos educativos definidos pelo turno e pelo contraturno, catalisando as tensões e dificuldades existentes entre eles. Tal "trânsito" nem sempre é fluido: segundo $42,5 \%$ dos coordenadores de programas de ampliação da jornada que responderam ao questionário digital na pesquisa $\mathrm{PRMBH}$, em suas

\footnotetext{
${ }_{8}$ Nas respostas aos questionários digitais da pesquisa PRMBH, evidenciouse que os diretores de escola e coordenadores/supervisores pedagógicos foram os profissionais mais frequentemente envolvidos nas discussões sobre a implantação do programa de ampliação da jornada; somente $49 \%$ dos respondentes apontaram que os professores foram envolvidos nas discussões.
} 
escolas não há conversas e/ou troca de informações envolvendo os profissionais do turno e do contraturno para um planejamento ou avaliação conjunta, com relação aos deveres de casa; e 29\% apontam, como um dos principais desafios para o acompanhamento aos deveres, a falta/dificuldade de comunicação entre educadores do contraturno e professores do turno regular.

Para além do dever de casa, a integração das propostas educativas desenvolvidas no "turno" e no "contraturno" em torno de um projeto político-pedagógico comum vem constituindo um desafio frequentemente reportado em diversos trabalhos acadêmicos (MATOS, 2011; FELÍCIO, 2011; CAVALIERE; MAURÍCIO, 2011; MAURÍCIO, 2012; LECLERC; MOLL, 2012). Isso inclui a comunicação entre as duas equipes com relação tanto aos propósitos gerais quanto aos aspectos cotidianos do funcionamento de cada um, ou, até mesmo, a superação dessa lógica de funcionamento em turnos. Tema presente em resultados de diversas pesquisas.

G. Uma das maiores dificuldades do programa é a integração com o regular. O Integral anda à parte, como se fossem duas escolas diferentes, como se fossem alunos diferentes, quando, na verdade, a proposta é a integração. Mas caminha muito paralelo... em todas as oficinas, todas as escolas a gente em geral observa isso. E são os mesmos alunos, as dificuldades são as mesmas... Por que não trabalhar conjuntamente? A gente não sabe o que acontece na escola, a escola não sabe o que acontece no Integral. Há um distanciamento muito grande (coordenador de área do Programa Escola em Tempo Integral de Mariana, em grupo focal de pesquisa realizada pelo grupo Teia. MEC, 2010b).

Essa integração entre turno e contraturno depende de condições estruturais, como, por exemplo, a existência de tempos e espaços comuns de trabalho entre os diferentes tipos de profissionais envolvidos. Cabe ressaltar que, frequentemente, as dificuldades começam na gestão da educação no âmbito do município, pois muitas vezes o projeto de tempo integral e os processos de ensino ditos "regulares" são geridos por equipes diferentes também nesse âmbito. Equipes essas que nem sempre conseguem atuar de modo articulado, distanciando-se por disputas políticas e ideológicas.

A própria necessidade de integração não é um consenso, como demonstra o tipo de questionamento que se sintetiza a seguir, a partir de questões formuladas, em dois diferentes encontros de formação, por dois educadores envolvidos em projetos de ampliação da jornada escolar:

H. Será que maior integração com o ensino regular seria realmente desejável? Ao trabalhar de modo mais articulado com a escola, ela não seria muito dominante e não haveria o risco de escolarizar demais as atividades do contraturno, retirando a liberdade que temos para manter um viés mais cultural?

Esse tipo de questionamento vai ao encontro dos depoimentos E e F, apresentados anteriormente, no sentido de que está subjacente a busca de resguardar a especificidade do trabalho desenvolvido no contraturno, em face do que é considerado como tipicamente escolar - ou seja, evitar, nas palavras empregadas no depoimento F, "uma repetição da escola".

A discussão que se coloca centralmente, então, dentre outras que poderiam ser abertas, é a do tipo de concepção que orienta os projetos de ampliação da jornada escolar. Nesse contexto, o projeto de ampliação da jornada tende a ser visto por muitos professores como uma medida específica para atender alunos em situação de maior vulnerabilidade e não como uma necessidade do próprio trabalho pedagógico ou uma escolha propriamente educacional (CAVALIERE, 2014). Em uma escola de tradição excludente como é a brasileira, na qual o fracasso na aprendizagem é creditado a déficits pessoais ou familiares e não visto como um problema de toda a comunidade escolar (PATTO, 1996), a extensão da jornada também não é vista como uma ação que diz respeito a todos. Em muitos casos, acaba contribuindo para estigmatizar ou perpetuar a estigmatização dessas crianças, que passam a ser chamadas de "crianças do projeto" e até mesmo culpabilizadas por "tumultuar a escola", como se constata no depoimento a seguir:

I. Parece que os estudantes no contraturno não fazem parte da escola. É comum ouvir: 'Aqueles meninos já chegaram para tirar o nosso sossego!'. Ou então: 'Os seus meninos chegaram. Toma conta deles para não tumultuar a escola' (coordenadora do contraturno, pesquisa PRMBH, questionário digital, 2014).

\section{DENÚNCIAS DA AMPLIAÇÃO DA JORNADA ESCOLAR A RESPEITO DOS DEVERES DE CASA}

J. Será que o aluno deve fazer o dever de casa na escola? Nesse caso, em que momento a família vai acompanhar esse filho? Temos casos de crianças cuja mochila vai para casa no final de semana e volta do mesmo jeito na segunda, indicando que os pais nem sequer a olharam. Tem mochila que parece uma lata de lixo de tão desorganizada. Se não tiverem que olhar o dever, o que esses pais vão olhar? (coordenadora de programa de ampliação da jornada, em encontro de formação, 2013).

K. A filosofia da Escola Integrada não é fazer dever de casa. Não é abraçar responsabilidade de pai, não 
é fazer papel de babá de luxo. (coordenadora de programa de ampliação da jornada, em encontro de formação, 2013).

L. Se a criança sempre fizer todos os Para Casa na escola, a grande maioria das famílias vai abandonar de vez seus papéis na vida escolar de seus filhos (coordenadora do programa de ampliação da jornada, questionário digital, PRMBH, 2014).

M. O Para Casa é a ponte que liga a escola e a família, e quando a Escola Integrada de certa forma assume parte dessa responsabilidade, a família se torna mais negligente com o compromisso de saber da vida escolar dos seus filhos (coordenadora do programa de ampliação da jornada, questionário digital, PRMBH, 2014).

Em geral, quando se discutem as funções dos deveres de casa, os primeiros aspectos comumente evocados estão ligados a finalidades cognitivas e pedagógicas (RAYOU, 2009; DESLANDES, 2009): reforço e consolidação das aprendizagens, fixação de conteúdos escolares, desenvolvimento de hábitos de estudo e da autonomia, dentre outras. Porém, os depoimentos acima indicam que, ao serem confrontados com a possibilidade de realização dos deveres na própria escola, não é a perda dessas funções que mais preocupa muitos educadores, mas sim de um possível canal de comunicação com as famílias. Mais do que isso, a perda de uma importante estratégia para provocar o seu envolvimento com a escolaridade dos filhos.

Tal constatação não constitui uma novidade, uma vez que essas funções "sociais" atribuídas aos deveres de casa já são reportadas pela literatura, que os aponta como o principal meio de interação ou "interface de colaboração" (SYMEOU, 2009, p. 82) entre famílias e escolas ou como uma das tecnologias sociais por meio das quais se estabelece uma teia de interações entre pais e professores (KRYGER e RAVN, 2009). Estas são utilizadas pelos últimos para tentar envolver mais diretamente os primeiros com a vida escolar dos filhos (CAILLET e SEMBEL, 2009). Porém, o que os referidos depoimentos parecem denunciar é que os educadores escolares já partem de uma avaliação negativa das famílias, vistas como negligentes e omissas, e defendem a realização dos deveres em casa como se fosse o último "trunfo" que lhes resta para compelir os pais a algum tipo de envolvimento. Cabe indagar até que ponto tal visão a respeito das famílias seria fundamentada em um real conhecimento de suas condições/modos de acompanhamento à escolaridade dos filhos ou seria baseada em estereótipos derivados de expectativas não atendidas; e, mais diretamente, no caso deste artigo, interessa questionar qual a eficácia de utilizar o dever de casa para obter maior envolvimento.
Segundo 57\% dos coordenadores do ensino regular que responderam ao questionário digital na pesquisa PRMBH, após a ampliação da jornada escolar houve, de modo geral, um aumento na frequência de realização dos deveres pelas crianças - sendo que na maior parte dos programas é disponibilizado um tempo para a execução desses deveres durante a jornada letiva. $\mathrm{Ou}$ seja, o fato de os deveres serem anteriormente enviados para casa não fazia com que as famílias necessariamente os acompanhassem e garantissem sua execução. Diante disso, cabe questionar a serviço de que devem estar, prioritariamente, os deveres de casa: da aprendizagem ou da responsabilização (rapidamente transformada em culpabilização) das famílias? Os debates gerados no contexto da ampliação da jornada escolar parecem denunciar o fato de que frequentemente se observa a segunda opção. Muitas vezes, os deveres são mantidos, nas escolas, praticamente por tradição, sem envolverem uma intencionalidade pedagógica clara e uma política explícita - e compartilhada pelos diferentes sujeitos do processo pedagógico (CARVALHO, 2004; RESENDE, 2012). Na pesquisa PRMBH, constatou-se que, em geral, a prescrição de deveres é muito pouco normatizada em documentos oficiais da escola. Os principais aspectos para os quais há critérios comuns em relação aos deveres - ou que são objeto de discussão em reuniões - são: indicação de que todos os professores devem prescrever deveres de casa; frequência com que devem ser prescritos os deveres; sanções ou tipos de encaminhamentos no caso de não realização dos deveres pelos alunos. Na maior parte dos casos, esses aspectos são combinados verbalmente e não estão registrados em documentos oficiais. Temas como o tempo médio que se espera que o aluno gaste por dia fazendo deveres de casa e os objetivos e critérios para elaboração e para correção dos deveres de casa são menos discutidos e orientados por definições comuns.

Isso não significa que por serem menos discutidos não sejam problemáticos. Na mesma pesquisa, 30,5\% dos coordenadores dos programas de ampliação da jornada que responderam ao questionário digital indicaram encontrar problemas na prescrição dos deveres (inadequação ao nível de aprendizagem dos alunos, incoerências ou falta de clareza de enunciados, etc.) como um dos desafios enfrentados para o acompanhamento a eles no contraturno. As duas observações abaixo, apresentadas por duas coordenadoras de programas de ampliação da jornada ao responderem ao questionário digital, ilustraram esse índice:

N. Em reunião com professores, já colocamos a inadequação, incoerências ou falta de clareza de atividades, a quantidade excessiva de Para Casa, o que as crianças reclamam "não sei" ou "não entendi". Após o encontro houve pequenina melhora 
nesses aspectos citados, porém continua o excesso de atividades nos livros que deveriam ser feitas em classe com orientações do professor (coordenadora do contraturno, questionário digital, PRMBH, 2014).

O. Na minha opinião o dever de casa é importantíssimo. A partir do momento que o professor deu a atividade para casa, dê ao aluno o retorno dessa importância. Acredito que muitos não o fazem porque não o acham importante. Muitos alunos não percebem a importância do dever de casa porque não é mostrado isso a ele. Será que o professor sabe realmente a importância do dever de casa? Se sabe, por que será que a maioria não 'cria'? Só mandam fazer os exercícios criados por outros. Muitas vezes, nem percebem erros de tipografia, o que dificulta a compreensão e a resolução dos mesmos (coordenadora do contraturno, questionário digital, PRMBH, 2014).

É interessante observar que esse tipo de problema na prescrição dos deveres provavelmente sempre tenha existido, mas antes era enfrentado pelas famílias no recesso do lar, permanecendo frequentemente silenciado, a não ser pelas polêmicas em reuniões de pais. Passando agora a emergir dentro do espaço-tempo da escola, tende a ganhar maior visibilidade. Trata-se, portanto, de outra "denúncia" da ampliação da jornada a respeito do dever de casa: muitas vezes, não merecendo maior atenção no planejamento pedagógico, pode ser mantido como uma tradição que, embora gerando expectativas em relação aos alunos e às famílias, tem seus objetivos comprometidos pela falta de uma prescrição mais criteriosa por parte dos professores (CARVALHO; NASCIMENTO; PAIVA, 2006).

Voltando à questão dessas expectativas em relação às famílias, a ampliação da jornada escolar, ao trazer os problemas relativos ao dever de casa para o interior da escola, contribui também para denunciar as tensões na divisão do trabalho educacional entre família e escola (CAVALIERE; COELHO; MAURÍCIO, 2013) e a necessidade de buscar novas formas de equacionar essa divisão na perspectiva de um efetivo compartilhamento. Nos depoimentos $\mathrm{J}$ a $\mathrm{M}$, percebe-se que os educadores escolares se queixam da transferência de responsabilidades da família para a escola, evidenciada, na perspectiva deles, pela ampliação da jornada escolar. Ao discutir a realização dos deveres na escola, um dos motivos que muitos educadores alegam para questioná-la é a falta de profissionais especializados para o acompanhamento. Ora, se os monitores e agentes culturais contratados pela escola não são considerados aptos a acompanhar os deveres, por que as famílias, que nas escolas públicas frequentemente têm baixos níveis de escolaridade, seriam? Por que tal acompanhamento deveria ser uma tarefa intrinsecamente das famílias? Esta não seria, também, uma transferência de reponsabilidades da escola - que tem a função específica de ensinar - para os pais?

Finalmente, uma última questão relacionada às demais é a da autonomia dos alunos para a realização dos deveres de casa. Uma das funções tradicionalmente atribuídas pelos educadores para tais deveres - inclusive no contexto da pesquisa PRMBH - é o desenvolvimento da autonomia. Porém, a realização dessas tarefas no contexto escolar parece estar trazendo à tona, também, o fato de que o modo como os deveres são agenciados pela escola parece não ser, de fato, focado nessa autonomia. Isso porque de alguma forma se conta sempre com a supervisão de alguém - sejam as mães/pais ou os demais responsáveis, sejam os profissionais do contraturno. E se espera sempre dessa supervisão mais do que assegurar um local e um tempo adequados para a execução das atividades - se assim não fosse, a "falta de preparação" dos profissionais para o acompanhamento não seria aventada. Tal "denúncia" dos programas de ampliação da jornada a respeito dos deveres de casa, além de se relacionar a questões já mencionadas acima, tais como a clareza de enunciados das tarefas, toca no âmago da problemática desses deveres, na forma como vêm sendo geridos, em geral, pelas escolas. Trata-se do fato de serem atividades homogêneas para grupos de alunos que necessariamente têm processos de aprendizagem heterogêneos (RESENDE, 2013), o que compromete sua adequação, faz com que o mesmo dever possa ser muito fácil para alguns alunos e muito difícil - portanto, inviável de ser realizado autonomamente - para outros.

\section{CONSIDERAÇÕES FINAIS}

Conforme anteriormente apontado, este artigo parte do pressuposto de que as questões suscitadas em relação aos deveres de casa no âmbito dos projetos de ampliação da jornada escolar "denunciam" desafios mais amplos relacionados a esses dois elementos - o modo como vem ocorrendo a ampliação da jornada escolar no Brasil e os deveres de casa em si, tal como têm sido agenciados no contexto dessa ampliação ou independentemente / anteriormente a esta. $\mathrm{O}$ artigo se concentra em apresentar algumas dessas "denúncias" a partir de dados obtidos na Região Metropolitana de Belo Horizonte, com base na premissa de que provavelmente os desafios identificados sejam comuns a outras realidades brasileiras.

Cabe ressaltar que, na pesquisa PRMBH, uma constatação relevante foi a de que o tempo de existência do programa de ampliação da jornada na escola é um importante fator - embora, evidentemente, não seja o único - para o equacionamento dos desafios. Em geral, a implantação do programa representa um momento de desestabilização no qual vários aspectos do funcionamento 
da escola são colocados em xeque. Mas, em vários casos, especialmente quando existe uma liderança atuante - seja da direção da escola, seja das equipes de coordenação -, observa-se que a continuidade do programa tende a fazer com que este seja progressivamente incorporado à cultura da instituição e permite que alternativas sejam construídas para fazer face aos problemas encontrados.

Do ponto de vista da ampliação da jornada, algumas alternativas identificadas visavam, principalmente, à maior articulação entre turno e contraturno, envolvendo medidas como viabilização de encontros e reuniões entre as duas equipes; contratação de supervisores/coordenadores pedagógicos em regime de 40 horas (portanto, presentes nas escolas nos dois turnos); contratação de professores da própria escola (e não somente de agentes culturais/ monitores) para atuar no contraturno; e, no caso da contratação de agentes culturais e monitores, busca de estabilidade para essa equipe (sendo a rotatividade um dos fatores que dificulta a integração com o turno) e criação de oportunidades de formação continuada, preferencialmente conjunta com a equipe do ensino regular.

Com relação aos deveres de casa, a maior parte dos educadores que responderam ao questionário digital indicaram que foram criadas formas de enfrentamento aos desafios, sendo citadas predominantemente as conversas ou reuniões com os alunos, professores e famílias incluindo encontros, geralmente não sistemáticos, entre as equipes do turno e do contraturno. Mencionaramse, também, de modo mais pontual: modificações no tamanho e na elaboração dos deveres para possibilitar sua realização com autonomia pela criança; formação dos monitores para acompanhamento; em um caso, "organização em equipe de professores para elaboração do dever, observando o tamanho, o tipo e o agrupamento necessário de alunos no tempo integral". Em algumas escolas foram criados murais ou cadernos de bilhetes para troca de informações entre os profissionais do turno e do contraturno a respeito dos deveres.

Em uma escola, especificamente, observou-se a elaboração de deveres comuns para todas as turmas do mesmo ano escolar em alguns dias da semana. Essa medida, tomada por iniciativa da coordenadora, tinha como objetivo facilitar o acompanhamento no contraturno, mas, segundo ela, contribuía também para maior unidade curricular entre as turmas. A necessidade de contemplar a realidade de cada turma ficaria resguardada pela prescrição de deveres específicos nos outros dias da semana. Uma alternativa que, embora possível, não se identificou diretamente, foi a prescrição de deveres comuns para grupos de alunos, considerando as necessidades de aprendizagem e a enturmação a ser feita no contraturno. Evidentemente, tal atividade exigiria mais planejamento e articulação entre as diferentes equipes.
Constata-se dessa forma que, se as questões relativas ao dever de casa no contexto de ampliação da jornada denunciam desafios mais amplos relativos a esses dois elementos, as referidas questões podem representar, também, oportunidades para que tais desafios sejam enfrentados e alternativas sejam criadas; e, principalmente, para que tanto a ampliação da jornada quanto o dever de casa sejam discutidos mais cuidadosamente no âmbito do projeto político-pedagógico de cada escola.

\section{REFERÊNCIAS}

BRASIL. Decreto no 6.253, de 13 de novembro de 2007, que dispõe sobre o Fundo de Manutenção e Desenvolvimento da Educação Básica e de Valorização dos Profissionais da Educação - Fundeb, regulamenta a Lei no 11.494, de 20 de junho de 2007, e dá outras providências. Diário Oficial da União, Brasília, DF, 14 nov. 2007.

BRASIL. Ministério da Educação/Secad. Educação integral/ educação integrada $\mathbf{e}(\mathbf{m})$ tempo integral: concepções e práticas na educação brasileira. Mapeamento das experiências de jornada escolar ampliada no Brasil. Brasília: MEC/Secad, 2010a. 128 p. (Série Mais Educação). Disponível em: <http://portal. mec.gov.br/index.php?option=com_content $\&$ view $=$ article $\&$ $\mathrm{id}=16727 \&$ Itemid=1119>. Acesso em: 12 set. 2015.

BRASIL. Ministério da Educação/Secad. Educação integral/ educação integrada e(m) tempo integral: concepções e práticas na educação brasileira. Mapeamento das experiências de jornada escolar ampliada no Brasil: estudo qualitativo - Mariana/ MG (Relatório de pesquisa). Belo Horizonte: UFMG, $2010 \mathrm{~b}$.

CAILLET, Valérie; SEMBEL, Nicolas. Points de vue et pratiques des partenaires du travail hors la classe: enseignants, parents, eleves. In: RAYOU, Patrick (Org.). Faire ses devoirs: enjeux cognitifs et sociaux d'une pratique ordinaire. Rennes: Presses Universitaires de Rennes, 2009. p. 33-70.

CARVALHO, Maria Eulina de Pessoa. Relações entre família e escola e suas implicações de gênero. Cadernos de Pesquisa, n. 110 , p. 143-155, jul. 2000.

CARVALHO, Maria Eulina de Pessoa. Escola como extensão da família ou família como extensão da escola? O dever de casa e as relações família-escola. Revista Brasileira de Educação, v. 25, p. 94-104, 2004.

CARVALHO, Maria Eulina de Paiva; NASCIMENTO, Conceição dos S.; PAIVA, Clotilde M. O lugar do dever de casa na sala de aula. Olhar de Professor, UEPG, v. 9, p. 341-357, 2006.

CAVALIERE, Ana Maria. Tempo de escola e qualidade na educação pública. Educação e Sociedade, Campinas, v. 28, n. 100, esp., p. 1015-1035, out. 2007.

CAVALIERE, Ana Maria. Escola pública de tempo integral no Brasil: filantropia ou política de Estado? Educação e Sociedade, Campinas, v. 35, n. 129, p. 1205-1222, out.-dez. 2014.

CAVALIERE, Ana Maria; MAURICIO, Lucia Velloso. Práticas de ampliação da jornada escolar no ensino fundamental: sobre modelos e realidades. In: Anais da 34a $\underline{\text { a }}$ Reunião Anual da Anped, Natal, 2011, v. 1. p. 1-15. Disponível em: $<$ http://34reuniao.anped.org.br/images/trabalhos/GT13/GT13163\%20int.pdf>. Acesso em: 16 maio 2017. 
CAVAlIERE, Ana Maria; COELHO, Ligia Martha; MAURÍCIO, Lúcia Velloso. Implicações da ampliação do tempo escolar nas relações entre família e escola. In: ROMANELLI, Geraldo; NOGUEIRA, Maria Alice; ZAGO, Nadir. Família \& escola: novas perspectivas de análise. Petrópolis/RJ: Vozes, 2013. p. 257-277.

DESLANDES, Rollande (Org.). International perspectives on student outcomes and homework: family - school community partnerships. New York: Routledge, 2009.

FELICIO, Helena Maria dos Santos. A integração curricular na Educação em Tempo Integral: perspectivas de uma parceria interinstitucional. In: Anais da 34⿳⺈ a Reunião Anual da Anped, Natal. 2011. Disponível em: <http://34reuniao.anped.org.br/ images/trabalhos/>. Acesso em: 15 abr. 2013.

HENRIQUES, Maria Eulália de Faria. Os trabalhos de casa na escola do 10 ciclo da Luz: estudo de caso. In: SILVA, Pedro (Org.). Escolas, famílias e lares: um caleidoscópio de olhares. Porto: Profedições, 2007.

KRYGER, Niels; RAVN, Birte. Homework in Denmark. What kind of links between family and school? In: DESLANDES, Rollande (Org.). International perspectives on student outcomes and homework: family-school-community partnerships. London and New York: Routledge, 2009. p. 7-24.

LECLERC, Gesuína F. Elias; MOLL, Jaqueline. Programa Mais Educação: avanços e desafios para uma estratégia indutora da educação integral e em tempo integral. Educar em Revista, Curitiba, n. 45, p. 91-110, jul./set. 2012.

MATOS, Sheila Cristina Monteiro. Os saberes diferenciados nas práticas educativas do Programa Mais Educação/Mais Escola: avanços e desafios. In: Anais da 34aㅡ Reunião Anual da Anped, Natal. 2011. Disponível em: <http://34reuniao.anped. org.br/images/trabalhos/>. Acesso em: 15 abr. 2013.

MAURÍCIO, Lúcia Velloso. Questões colocadas pela ampliação da jornada escolar no Brasil. In: Anais da 35a Reunião Anual da Anped, Porto de Galinhas, 2012. Disponível em:
$<$ http://35reuniao.anped.org.br/trabalhos/117-gt13>. Acesso em: 15 abr. 2013.

NOGUEIRA, Martha Guanaes. Tarefa de casa - uma violência consentida? São Paulo: Edições Loyola, 2002.

PATTO, Maria Helena Souza. A produção do fracasso escolar: histórias de submissão e rebeldia. São Paulo: T. A. Queiroz, 1996.

PAULA, Flávia Anastácio. Lições, deveres, tarefas, para casa: velhas e novas prescrições para professoras. $241 \mathrm{f}$. Dissertação (Mestrado) - Faculdade de Educação. Universidade Estadual de Campinas, Campinas, 2000.

RAYOU, Patrick (Org.) Faire ses devoirs: enjeux cognitifs et sociaux d'une pratique ordinaire. Rennes: Presses Universitaires de Rennes, 2009.

RESENDE, Tânia de Freitas. Entre escolas e famílias: revelações dos deveres de casa. Paidéia, Ribeirão Preto, v. 18, n. 40, p. 385-398, 2008.

RESENDE, Tânia de Freitas. Dever de casa, espelho de desigualdades educacionais e sociais. Educação em Revista, Belo Horizonte, v. 28, p. 159-184, 2012.

RESENDE, Tânia de Freitas. Pela "janela" do dever de casa, o que se vê das relações entre escolas e famílias? In: NOGUEIRA, Maria Alice; ROMANELLI, Geraldo; ZAGO, Nadir. Família e escola - novas perspectivas de análise. Petrópolis: Vozes, 2013. p. 199-219.

SYMEOU, Loizos. Mind the gap! Greek-cypriot parents and their children's homework. In: DESLANDES, Rollande (Org.). International perspectives on student outcomes and homework: family-school-community partnerships. London and New York: Routledge, 2009. p. 76-94.

Recebido em 06-06-2017

Aprovado em 21-08-2017. 